\title{
SHORT- AND LONG-TERM EFFECTS OF OXYTOCIN ON QUALITY AND QUANTITY OF SEMEN FROM RAMS
}

\author{
T. W. KNIGHT AND D. R. LINDSAY \\ Institute of Agriculture, University of Western Australia, \\ Nedlands, 6009
}

(Received 10th March 1969)

\begin{abstract}
Summary. Intravenous injection of oxytocin into rams immediately before collection of semen with an artificial vagina, resulted in an increase in the volume of semen and the number of spermatozoa per ejaculate. After 6 weeks, during which the rams received 35 i.u. oxytocin per week, the volume of semen and the number of spermatozoa per ejaculate declined to the level of the non-treated rams and this decline was maintained for the next 4 weeks. The percentage of abnormal spermatozoa in semen from rams treated with oxytocin increased significantly $(P<0.001)$ in the 7 th week. The concentration of fructose in the semen and the libido were not affected by oxytocin. When an electroejaculator was used for making collections, the volume of semen increased after oxytocin injection $(P<0.05)$, with a maximum response at 10 i.u. oxytocin.

Oxytocin appeared to have an immediate stimulating effect on the ejection of spermatozoa and seminal plasma during emission and a long term adverse effect on spermatogenesis.
\end{abstract}

\section{INTRODUCTION}

The rôle of oxytocin in male reproductive function is equivocal. It has been shown that the degree of sexual excitation before collection is important in determining the volume and quality of semen ejaculated by bulls (Milovanov \& Smirnov-Ugrumov, 1940). High levels of oxytocin have been found in samples of blood taken from bulls immediately before and immediately after service compared with those from bulls which were not sexually excited (Bereznev, 1963). Injection of oxytocin immediately before service (Milovanov, Bereznev \& Gorohov, 1962) increased the volume of semen from both bulls and rabbits. In some cases, this increase was accompanied by an increase in the concentration of spermatozoa (Milovanov et al., 1962) but in others, the sperm concentration decreased (Kihlstrom \& Melin, 1963).

In addition to these immediate effects, exogenous oxytocin has been shown to increase urinary levels of gonadotrophins in mature rabbits (Martini, Miro, 
Pecile \& Saito, 1959). It also augments the stimulating effect of FSH on the seminiferous tubule growth of immature rabbits (Armstrong \& Hansel, 1961). In male rats, it has been found that oxytocin caused a small increase in testicular size, and an enhanced excretion of 17-ketosteroids (Shibusawa, Saito, Fukuda, Kawai, Yamada \& Tomizawa, 1955).

These findings suggest that oxytocin could have an effect on spermatogenesis as well as a short term effect on the amount of semen expelled during ejaculation. The experiments described here were designed to investigate the shortand long-term effects of oxytocin on quality and quantity of semen from rams.

\section{MATERIALS AND METHODS}

The experiments were carried out at the University of Western Australia's field station at Shenton Park between May and October 1967.

\section{Animals}

Two-year-old Merino rams were used. They were managed under natural grazing conditions.

Ewes were ovariectomized and oestrus was induced when required by injecting $200 \mu \mathrm{g}$ oestradiol after priming with progesterone (Robinson, Moore \& Binet, 1956).

\section{Collection techniques}

Semen collections were made with an artificial vagina (AV) in Exp. 1, while the electro-ejaculator was used for collections in Exp. 2.

\section{Injection of oxytocin}

To minimize disturbance of the rams during collection with the AV, oxytocin (Pitocin, Parke Davis) was administered through a No. 2 Sterivac cannula which was inserted into the external jugular vein on the morning of the collections. When collections were being made with the electro-ejaculator, the oxytocin was injected directly into the external jugular vein. In both cases, semen collections were made within $5 \mathrm{~min}$ of the injections.

\section{Treatment of semen samples}

The volume of semen was determined, after which a $0.02-\mathrm{ml}$ sample of semen was diluted in $4 \mathrm{ml}$ of $0.9 \% \mathrm{NaCl}$ containing $0.004 \%$ formalin. From this sample, concentration of the spermatozoa was determined using a haemocytometer.

As an indication of testosterone levels (Mann, 1964), concentration of fructose in semen was determined colorimetrically by Glover's (1956) modification of the Seliwanoff reaction (Mann, 1948). Since fructose is a constituent of seminal plasma and not of spermatozoa, fructose levels were expressed as the concentration in the seminal plasma rather than in the semen (Glover, 1956). The volume of seminal plasma was computed using the estimate of $6.5 \times 10^{-11}$ 
$\mathrm{ml}$ for the volume of one spermatozoon (Mann, 1952, personal communication cited by Glover, 1956).

The proportion of morphologically abnormal spermatozoa was estimated on all samples collected in Exp. 2 and on those taken after the 5th week in Exp. 1 from counts made on semen smears stained with eosin-nigrosin. The most common abnormalities observed were spermatozoa with reflexed tails and an occasional tailless spermatozoon.

\section{Measurement of libido}

Libido was assessed by mating rams singly with oestrous ewes and recording the number of copulations which each ram completed in a 90 -min test period. These matings were made in pens of equal size, using ewes of approximately equal size and age, and oestrus was induced with identical hormone treatments. Each pen was screened to preclude visually stimulated responses.

\section{Experiment 1}

Twelve rams were divided into two groups (A and B) and two semen samples were collected $1 \mathrm{hr}$ apart on the same day of each week using an AV. Following the collections, each ram was mated with an oestrous ewe to test for libido.

During the first 10 weeks, rams of Group A received 7 i.u. of oxytocin before each semen collection and every $30 \mathrm{~min}$ during the libido test. Thus, each of the rams in Group A received a total of 35 i.u. of oxytocin per week while the rams of Group B acted as non-treated controls. The treatments were reversed for the 11th and 12th weeks and, thereafter, all treatment ceased. A final collection was made from both groups of rams during the 16th week.

\section{Experiment 2}

Another group of twelve rams was divided into four subgroups and, in accordance with a $4 \times 4$ latin square design, the following treatments were imposed: $0,5,10$ and 20 i.u. of oxytocin given before each semen collection. Each period lasted 1 week during which two semen samples were taken, using an electro-ejaculator.

\section{Statistical analysis}

Exp. 1. A preliminary analysis of variance for semen volume, concentration and the number of spermatozoa per ejaculate, was carried out on data obtained over the first 10 weeks to examine differences due to time and treatment. Regression lines were fitted to the mean weekly data for semen volume, concentration and number of spermatozoa per ejaculate for the two groups of rams. A comparison of the regression coefficients for treatment and control groups was used to indicate the effect of oxytocin with time.

The effect of oxytocin on the mean weekly seminal plasma concentration of fructose, on the mean number of ejaculations per $90 \mathrm{~min}$, and on the percentage of spermatozoa with reflexed tails during the 7 th to 10 th weeks, was examined by analysis of variance.

Exp. 2. Results were subject to analysis of variance. 


\section{RESULTS}

\section{Experiment 1}

Preliminary analysis showed that samples taken at first or second ejaculation did not differ significantly in volume, concentration or total number of spermatozoa and therefore means of the two samples were used for regression analysis
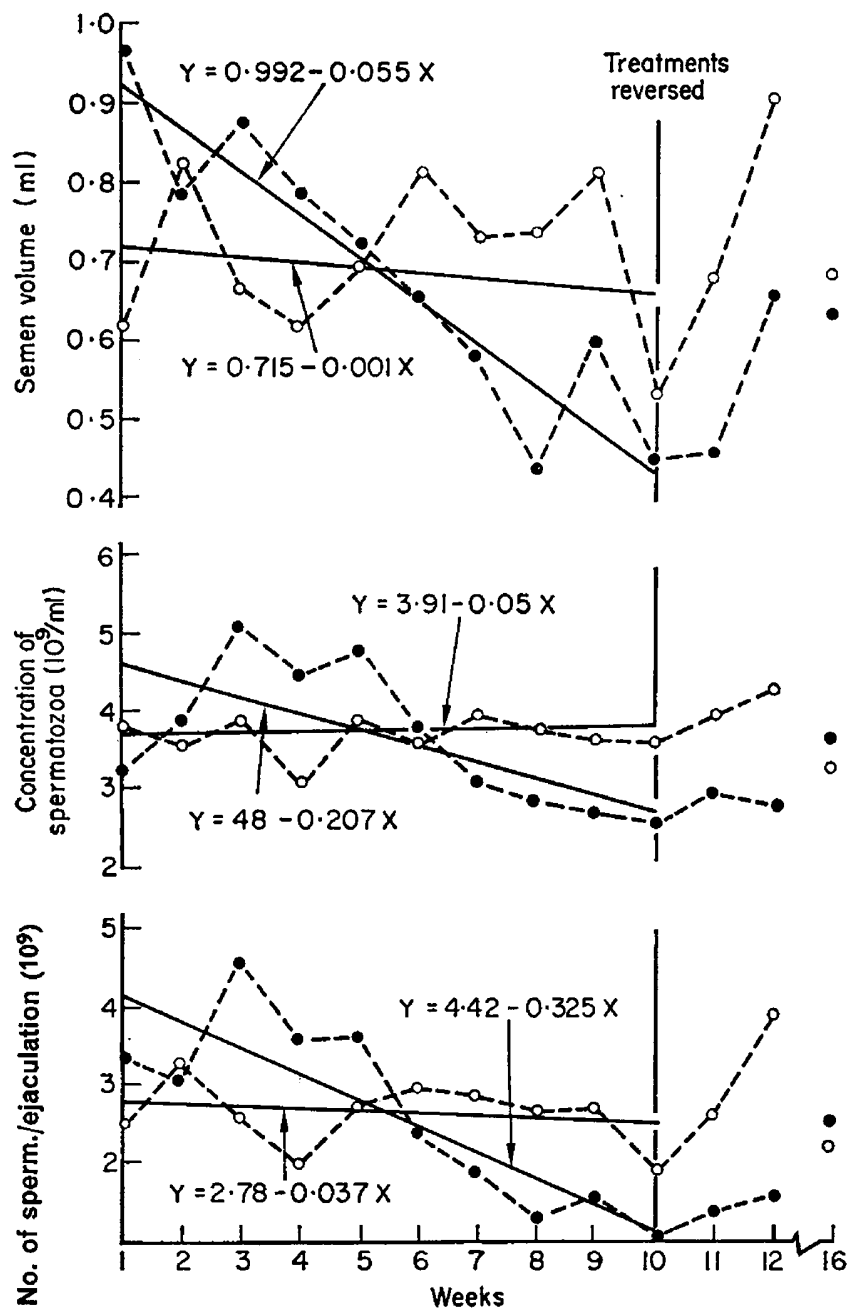

TEXT-FIG. 1. The effect of intravenous injections of oxytocin on semen volume, concentration of spermatozoa and number of spermatozoa per ejaculate. Each point represents the mean of two ejaculates from six rams. - 7 i.u. oxytocin before each ejaculate; 0 , controls.

(Text-fig. 1). This showed that there were significant effects of oxytocin treatment with time, on volume of semen $(P<0.001)$ and number of spermatozoa per ejaculate $(P<0.01)$. Initially, oxytocin injections increased the volume of the semen and the number of spermatozoa per ejaculate but by the 6th week, 
the levels of these parameters had declined to those of the control animals. This decline continued for a further 4 weeks. The concentration of spermatozoa in the semen of the treated rams followed a similar pattern but the difference was not statistically significant $(0 \cdot 1>P>0 \cdot 05)$.

When oxytocin was injected into the control rams during the 11 th and 12 th weeks, the volume of their semen, concentration and number of spermatozoa per ejaculate increased. Six weeks after the cessation of oxytocin injections, the semen characteristics of both groups of rams were indistinguishable.

In the 6th week of Exp. 1, when the examination of semen smears for abnormal spermatozoa commenced, there was virtually no difference between the treated and untreated groups of rams. Between Weeks 7 and 10, there was a highly significant increase in the percentage of abnormal spermatozoa in the semen from the oxytocin-treated group (Text-fig. 2), the main deformity being



TExT-FIG. 2. The percentage of abnormal spermatozoa in semen collected with an AV. Each point is the mean for six rams. $\Delta$, Oxytocin treatment; $\Delta$, controls.

tail reflexing $(P<0.001)$. This level of abnormality continued until the end of Week 12. By the 16th week, the percentage of abnormal spermatozoa had declined in these animals but simultaneously increased in the original control animals that had received oxytocin during Weeks 11 and 12 only. Tailless spermatozoa represented less than $1 \%$ of the abnormalities from both groups of rams throughout the experiment.

Libido and concentration of fructose in the seminal plasma were not affected by oxytocin treatment.

\section{Experiment 2}

There was a significant increase $(P<0.05)$ in volume of semen per ejaculate when oxytocin was injected before electro-ejaculation. Levels of 5,10 and 20 i.u. oxytocin induced $0.88,1.26$ and $1.19 \mathrm{ml}$ of semen per collection, respectively, compared with $0.59 \mathrm{ml}$ from the non-injected controls. Although the number of spermatozoa per ejaculate increased after the injection of oxytocin, 
the effect was not significant. There were no further increases in volume of semen or number of spermatozoa per ejaculate at doses higher than 10 i.u.

Concentration of spermatozoa did not change significantly as a result of oxytocin injections but there was a highly significant decline $(P<0 \cdot 01)$ in the concentration of spermatozoa over the 4-week period.

The percentage of abnormal spermatozoa and the concentration of fructose in the seminal plasma were not affected by the oxytocin injections during the 4-week collection period.

\section{DISGUSSION}

The immediate response to oxytocin injection was to increase the volume, concentration and number of spermatozoa per ejaculate in rams. These findings agree with those of Milovanov et al. (1962) in bulls and in rabbits. On the other hand, Ewy, Bielanski \& Zapletal (1963) showed that although oxytocin caused an increase in the flow of spermatozoa from the cannulated vas deferens of rams, the maximum flow did not occur until some 10 to $40 \mathrm{~min}$ after injection. In both experiments, increases in the volume of the ejaculate were obtained less than $5 \mathrm{~min}$ after injection of oxytocin. Milovanov et al. (1962) also found that the response to oxytocin was only obtained if the semen collections were made within $5 \mathrm{~min}$ of the injection of oxytocin.

In the majority of cases, these increases were accompanied by increases in the output of both seminal plasma and spermatozoa. This suggests that the effect recorded here was due to increased contraction of the upper genital tract and the accessory glands during emission, although increases in the spontaneous contractions due to oxytocin injections have been found by Bereznev (1963, 1964) as far back in the tract as the epididymis and testis.

Quantitatively, dose levels of oxytocin for which responses were recorded are similar to those used in the bull by Bereznev (1964). Doses above 10 i.u. were unsuccessful in bulls when semen was collected by AV, and Bereznev (1964) attributed this to unco-ordinated emissions during the pre-copulatory phase. In order to preclude this possibility when determining dose-response relationships in rams, collections were made by electro-ejaculation. Semen output response increased to a maximum at a dose of 10 i.u. oxytocin, but was unchanged at a dose of 20 i.u.

The timing of the changes in semen characteristics following weekly injections of 35 i.u. oxytocin strongly suggests that oxytocin was directly or indirectly inhibiting the early stages of spermatogenesis. Dawson (1958) demonstrated that in rams, the interval from the first mitotic division of the spermatogonia to the first appearance of spermatozoa in the ejaculate was 45 to 49 days. In this experiment, volume of semen, concentration of spermatozoa and numbers of spermatozoa declined after the 6th week and the count of abnormal spermatozoa increased after the 7 th week. The concentration of fructose in seminal plasma, which is dependent on the circulatory testosterone level (Mann, 1964; Moule, Braden \& Mattner, 1966) and so on ICSH level (Greep, 1961), was not affected by oxytocin injections. Thus, the adverse effects of oxytocin do not appear to be related to changes in either the testosterone or the ICSH level. 
No increase in libido was measured in oxytocin-treated rams, despite the suggestion that such increases occur in the bull (Bereznev, 1964) and the fact that Melin \& Kihlstrom (1963) have shown that rabbits mate more frequently over a $30-\mathrm{min}$ test period following oxytocin injections.

\section{ACKNOWLEDGMENTS}

This work is part of a programme on ram behaviour and fertility supported by the Australian Meat Research Committee. One of us (T.W.K.) is indebted for a scholarship to the Australian Meat Research Committee.

\section{REFERENCES}

Armstrong, D. T. \& Hansel, W. (1961) Effect of hormone treatment on testes development and pituitary function. Int. F. Fert. 3, 296.

Bereznev, A. P. (1963) Oxytocin - a stimulator in the semen production of bulls. Anim. Breed Abstr. (1965) 33, 67.

Bereznev, A. P. (1964) The rôle of oxytocin in the process of ejaculation in bulls. 5 th int. Congr. Anim. Reprod. A.I. (Trento), Vol. VI, p. 101.

Dawson, R. M. C. (1958) The labelling of ram semen in vivo with radio-active phosphate and [carboxy$\left.{ }^{14} \mathrm{C}\right]$ stearic acid. Biochem. 7. 68, 512.

EwY, Z., BIELANSKI, W. \& ZAPLETAL, Z. (1963) Influence of oxytocin on spermatozoa transport in the ductus deferens of the ram. Bull Acad. pol. Sci., Cl. II, Serr. Sci. biol. 11, 145.

Glover, T. D. (1956) The effect of scrotal insulation and the influence of breeding season upon fructose concentration in the semen of the ram. F. Endocr. 13, 235.

GREEP, R. O. (1961) Physiology of the anterior hypophysis in relation to reproduction. In: Sex and Internal Secretions, 3rd edn. Ed. W. C. Young. Baillière, Tindall \& Cox, London.

Kinlstrom, J. E. \& Melin, P. (1963) Influence of oxytocin upon some seminal factors in the rabbit. Acta physiol. scand. 59, 363.

Mans, T. (1948) Fructose content and fructolysis in semen. Practical application in the evaluation of semen quality. F. agric. Sci., Camb. 38, 328.

ManN, T. (1964) The biochemistry of semen and of the male reproductive tract, 2nd edn, p. 242. Methuen, London.

Martini, L., Miro, L., Pecirle, A. \& Saito, S. (1959) Neurohypophysial hormones and release of gonadotrophins. F. Endocr. 18, 245.

Melin, P. \& Kinlstrom, J. E. (1963) Oxytocin on sexual behaviour in male rabbits. Endocrinology, 73, 433.

Milovanov, V. K., Bereznev, A. P. \& Gorohov, L. N. (1962) The effect of oxytocin on the reproductive system of male livestock. Anim. Breed. Abstr. (1964) 32, 101.

Milovanov, V. K. \& Smirnov-Ugrumov, D. V. (1940) Zivotnov vet. Delo, 5, 138. Cited by Gross, B. A. and Glover, T. D. (1958) The hypothalamus and seminal emission. F. Endocr. 16, 385.

Moule, G. R., BRADEN, A. W. H. \& MATTNER, P. E. (1966) Effects of season, nutrition and hormone treatment on the fructose content of ram semen. Aust. F. agric. Res. 17, 923.

Robinson, T. J., Moore, N. W. \& Binet, F. E. (1956) The effect of the duration of progesterone pretreatment on the response of the spayed ewe to oestrogen. F. Endocr. 14, 1.

Shibusawa, K., Satto, S., Fuxuda, M., Kawai, T., Yamada, H. \& Tomizawa, K. (1955) Endocr. jap. 2, 183. Cited by Benson, G. K. \& Folley, S. J. (1957) Effect of oxytocin on mammary gland involution in the rat. F. Endocr. 16, 189. 